\title{
Optimal Financing Order Decisions of a Supply Chain under the Retailer's Delayed Payment
}

\author{
Honglin Yang, ${ }^{1}$ Ya Yu, ${ }^{1}$ Yong Zha, ${ }^{2}$ and Jijun Yuan $^{3}$ \\ ${ }^{1}$ School of Business and Administration, Hunan University, Lusan Southern Avenue, Yuelu District, Changsha, Hunan 410082, China \\ ${ }^{2}$ School of Management, University of Science and Technology of China, Hefei, Anhui 230026, China \\ ${ }^{3}$ School of Finance, Guangdong University of Finance and Economics, Guangzhou, Guangdong 510320, China
}

Correspondence should be addressed to Honglin Yang; ottoyang@126.com

Received 30 April 2014; Accepted 19 June 2014; Published 13 July 2014

Academic Editor: Xiaohang Yue

Copyright (C) 2014 Honglin Yang et al. This is an open access article distributed under the Creative Commons Attribution License, which permits unrestricted use, distribution, and reproduction in any medium, provided the original work is properly cited.

\begin{abstract}
In real supply chain, a capital-constrained retailer has two typical payment choices: the up-front payment to receive a high discount price or the delayed payment to reduce capital pressure. We compare with the efficiency of optimal decisions of different participants, that is, supplier, retailer, and bank, under both types of payments based on a game equilibrium analysis. It shows that under the equilibrium, the delayed payment leads to a greater optimal order quantity from the retailer compared to the up-front payment and, thus, improves the whole benefit of the supply chain. The numerical simulation for the random demand following a uniform distribution further verifies our findings. This study provides novel evidence that a dominant supplier who actively offers trade credit helps enhance the whole efficiency of a supply chain.
\end{abstract}

\section{Introduction}

Currently, many enterprises, especially some companies with small capital sizes, still face a financing difficulty. This has been becoming a main bottleneck to block the development of enterprises. Due to the lack of capital, enterprises are quite difficult to grasp their potential business opportunities. This further leads to a lower possibility that enterprises obtain business loans [1]. Finding a way out of this dilemma will efficiently improve enterprise operation. To solving this issue, a considerable number of studies begin to concentrate on a supply chain system. They discussed how to utilize the credit of a dominant supplier to help its retailers gain bank's loans and how to use the inventories or accounts receivable as a mortgage to realize financing [2]. The literature [3] also proposed the internal financing in a supply chain instead of the external financing. The internal financing is also called trade credit and has been becoming a popular financing mode in practices.

In a real supply chain, a capital-constrained retailer generally takes two kinds of payments to treat with its short capital. One is the up-front payment so that it can get more price discount. Another is the delayed payment to buffer its capital pressure. When taking the up-front payment, the retailer often needs to loan from a bank before its purchase. The delayed payment actually is an internal financing that a supply chain's participants provide. The literature [4] first incorporated the insufficient capital into the optimal of the product and inventory. By investigating how the assetbased financing affects inventory decisions, they discussed the retailer's optimal order quantity and the bank's optimal interest rates. The literature [5] analyzed the influence of a retailer's working capital on the operation decision of a supply chain. They concluded that the leverage ratio of an optimal debt-to-market-value is negatively correlated with optimal inventory decisions. In addition, the literature [6] utilized the newsvendor model to examine how a retailer's owned capital affects its optimal order quantity. Meantime, the literature [7] analyzed a simple supply chain including a supplier, a capital-constrained retailer, and a bank and depicts the relationship among the optimal order quantity, wholesale price, and financing interest rate. Following this vein, the literature [8] constructed a multiperiod inventory model to investigate the optimal inventory and financing strategies 
under the participant risk aversion. All these studies focused on the up-front payment. While a retailer chooses the delayed payment, what is the optimal decisions of a supply chain is worthy of further examination.

In the developed capital markets, the trade credit is playing a crucial role in a supply chain operation [9]. The most retailer delayed payments actually are the trade credit provided by its supplier. As a supplement, the literature [10] investigated the retailer's optimal order quantity under a delayed payment. They found that the order time interval and order quantity increase as the annual cost decreases. Meantime, the literature [11] also found that there exists close relationship among the credit period, order quantity, and total cost. The literature [12] updated their study from a discrete model to a continuous model. From an aspect of the equilibrium, the literature [13] analyzed a simple supply chain involving a retailer and a customer. We notice that the studies, as mentioned above, contain an assumption that the retailer pays no additional cost for its delay. It seems unreasonable in real trade. This research gap supplies a possible improvement that considers a delayed compensation interest rate under the delayed payment.

To discover the difference between both payment strategies, the literature [14] incorporated the bank credit into the decision in which the retailer pays the principal while the supplier pays the interest. The literature [15] compared the efficiency of a bank financing when the supplier's price discount is viewed as an external variable. The literature [16] assumed that most wholesalers and suppliers choose commercial credit. They find that the supplier could achieve a higher return by designing a commercial credit contract prior to the trade. In addition, the literature [17] compares the supplier's optimal product and financing decision and finds that the initial capital of a supply chain is related to their financing cost. Further, the literature [18] investigates the retailer's optimal order quantity over two phases under a delayed payment. They conclude that the flexible payment could make a retailer earn more benefit. However, existing literature only investigates the supplier's or the retailer's optimal decision but does not consider the whole efficiency of a supply chain under the up-front and delayed payment.

In this paper, we analyze the whole efficiency of a supply chain to discover which of the retailer's payment strategy is better. The supply chain with capital-constrained participants generally has two financing options: get loans from a bank or from its supplier. The former helps participants complete the up-front payment to gain a higher discount. The latter actually is a trade credit and helps participants weaken their capital pressure. To find out the payment with a higher efficiency, we investigate a simply supply chain with a bank, a supplier, and a capital-constrained retailer. We aim to provide an efficient financing strategy to improve on a capitalconstrained supply chain.

The remainder of this paper is organized as follows. Section 2 illustrates two different kinds of financing modes in a simple supply chain and designs the model variables and assumptions. Section 3 examines a retailer optimal order

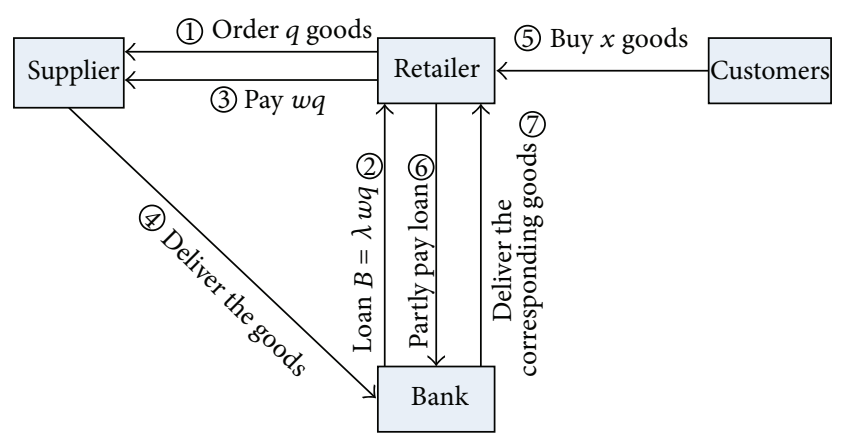

Figure 1: Financing order mode under the up-front payment.

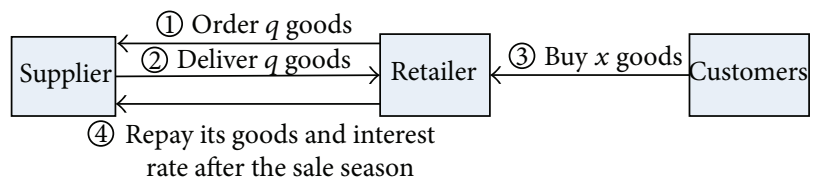

FIGURE 2: Financing order mode under the delayed payment.

quantity under the up-front and delayed payment. The supplier's optimal decisions, including the delayed compensation interest rate and discount price, are discussed in Section 4. Section 5 applies a numerical simulation to verify the previous theoretical results. Section 6 concludes with a discussion.

\section{Financing Mode and Variable Design}

2.1. Financing Mode under the Retailer's Up-Front and Delayed Payment. We here consider a simple supply chain with a bank, a capital-constrained retailer, and a supplier. Under the up-front payment, the retailer needs to borrow from a bank and pays its order goods in advance. Once the retailer cannot repay its interest and principle in time, it will go bankrupt. Due to the up-front payment, the retailer enjoys a price discount. Figure 1 illustrates this trade process. The capital-constrained retailer uses its order goods as a mortgage to loan $B=\lambda w q$ from a bank, where $\lambda$ is the leverage ratio, $w$ is the retailer's discount price, and $q$ is its order goods [7]. The number shown in Figure 1 denotes the trade process.

Most supply chains are with a typical pattern " $1+N$." The core enterprise " 1 " leads " $N$ " other enterprises. Under certain situations, this core enterprise also provides its " $N$ " capitalconstrained enterprises with internal financing, namely, its trade credit. For example, a dominant supplier agrees its retailer to repay its goods at the end of the sale season. If the retailer has no enough money at that time to repay its borrowing, it will go bankrupt. This is a typical delayed payment in which the capital-constrained retailer does not enjoy a discount price. Figure 2 depicts the trade process of a simple supply chain under the delayed payment.

2.2. Variables and Assumptions. The literature [7] examines the optimal decisions of a simple supply chain under the up-front payment. The retailer uses the bank loans to order products in advance and enjoys the supplier's price discount. 
This paper aims to compare the efficiency of the up-front payment with the delayed payment. Therefore, we still adopt the variables in the literature [7] except additional variables we limn the delayed payment. The definitions of all variables are as follows.

c: Supplier's unit producing cost.

$w$ : Supplier's unit discount price that provides its retailer. It is a supplier's decision variable.

$p$ : Retailer's unit selling price.

$q_{b}$ : Order quantity under the up-front payment. It is a retailer's decision variable.

$q_{s}$ : Order quantity under the delayed payment. It is a retailer's decision variable.

$y$ : Retailer's owned capital. It satisfies $y \leq w q$. This means the retailer's capital is not enough to pay its order quantity.

$R_{f}$ : Risk-free interest rate of a certain capital market.

$R_{r}$ : Loan interest rate of a bank.

$R_{s}$ : Delayed compensation interest rate required by a supplier. It is a supplier's crucial decision variable under the delayed payment. As one knows well, when a dominant supplier permits its retailer to pay at the end of the sale season, it actually bears operation risks and probably loses other investment returns. Hence, the retailer's delayed payment needs to include an additional interest to compensate them $[16,19]$.

$x$ : Market demand. It is a nonnegative and continuous random variable. $F(x)$ denotes a cumulative distribution function with an increasing failure rate (IFR). Hence, $\bar{F}(x)=1-F(x)$ is viewed as a survival function. If a retailer order 10 products, this hints that under an uncertain market demand, it is easier to sell 5 products than 10 products. $\bar{F}(x)$ decreases as $x$ increases.

$\pi_{r}$ : Retailer's benefit.

$\pi_{s}$ : Supplier's benefit.

Here $c \leq w \leq w\left(1+R_{s}\right) \leq p$. For simplicity, we make the following assumptions.

Assumption 1. The order goods are perishable and the unsold at the end of the sale season has no salvage value.

Assumption 2. The bank agrees to offer loans when it can earn benefit.

Assumption 3. All the participants in a supply chain are risk neutral and rational. They have symmetrical and consistent information.

\section{Retailer's Optimal Decision under the Delayed Payment}

The literature [7] examines the participants' optimal decisions under the up-front payment. Here we analyze the optimal decisions under the delayed payment. This means that the supplier uses its trade credit to solve the retailer's insufficient capital.

3.1. Retailer's Optimal Order Quantity under the Delayed Payment. The supplier provides a trade credit to retailer and its retailer is permitted a delayed payment at the end of the sale season. The retailer generally does not enjoy a price discount. And when the retailer repays, it needs to include an additional interest to compensate its supplier. Hence, the retailer's expected revenue under the delayed payment is as follows:

$$
E \pi_{r}=E\left[p \min (x, q)+y\left(1+R_{f}\right)-w q\left(1+R_{s}\right)\right]^{+},
$$

where $[z]^{+}=\max (z, 0)$ and $R_{s}$ denotes the retailer's compensation interest rate. Similar to the analysis of the upfront payment in the literature [7], we derive the critical condition that the retailer does not go bankrupt under the delayed payment.

For simplicity, the unsold product is assumed no salvage value. Let $\widehat{x}_{2}$ be the retailer's critical market demand. When $x \leq q$, the market cannot absorb all order quantity. We get the demand criticality $\widehat{x}_{2}=\left(w q\left(1+R_{s}\right)-y\left(1+R_{f}\right)\right) / p$ according to $\pi_{r} \geq 0$. Once $x \geq \widehat{x}_{2}$, the retailer never goes bankrupt. This is since the retailer's payment $w q\left(1+R_{s}\right)$ is less than its benefits, which consists of a risk-free return $y\left(1+R_{f}\right)$ and a sale income $p \min (x, q)$.

When $x=0$ and $q \geq y / w$, the market has no demand. And the retailer's capital is not enough to purchase order quantity. Similarly, we derive the critical order quantity $\widehat{q}_{2}=$ $y\left(1+R_{f}\right) / w\left(1+R_{s}\right)$ according to $\pi_{r} \geq 0$. When $q \leq \widehat{q}_{2}$, the retailer would never go bankrupt.

Equation (1) is further rewritten:

$E \pi_{r}= \begin{cases}p \int_{0}^{q} \bar{F}(x) d x+y\left(1+R_{f}\right)-w q\left(1+R_{s}\right), & q \leq \widehat{q}_{2}, \\ p \int_{\widehat{x}_{2}}^{q} \bar{F}(x) d x, & q>\widehat{q}_{2} .\end{cases}$

When $q \leq \widehat{q}_{2}, E \pi_{r}=p \int_{0}^{q} \bar{F}(x) d x+y\left(1+R_{f}\right)-w q(1+$ $\left.R_{s}\right) \geq 0$. The retailer never falls into bankruptcy. By taking $d E \pi_{r} / d q=0$, we get $p \bar{F}(q)-w\left(1+R_{s}\right)=0$ and further obtain the retailer's optimal order quantity $q_{s}^{*}=\bar{F}^{-1}\left(w\left(1+R_{s}\right) / p\right)$. Appendix A gives the proof of the equation $E[\min (x, q)]=$ $\int_{0}^{q} \bar{F}(x) d x$.

When $q>\widehat{q}_{2}$ and only when $x>\widehat{x}_{2}$, the retailer does not go bankrupt. This means $E \pi_{r} \geq 0$ and $\max \left[0, p \int_{0}^{\widehat{x}_{2}} \bar{F}(x) d x+\right.$ $\left.y\left(1+R_{f}\right)-w q\left(1+R_{s}\right)\right]=0$. Further, we get $E \pi_{r}=$ $p \int_{0}^{q} \bar{F}(x) d x+y\left(1+R_{f}\right)-w q\left(1+R_{s}\right)=p \int_{\bar{x}_{2}}^{q} \bar{F}(x) d x$. Вy taking $d E \pi_{r} / d q=0$, we obtain $p \bar{F}(q)-w\left(1+R_{s}\right) \bar{F}\left(\widehat{x}_{2}\right)=$ 0 . Further, we compute the retailer's optimal order quantity $q_{s}^{*}=\bar{F}^{-1}\left[\left(w\left(1+R_{s}\right) / p\right) \bar{F}\left(\widehat{x}_{2}\right)\right]$.

The literature $[4,16]$ gives four intervals for the retailer's optimal order quantity. These intervals are built on the case that excludes the capital-constrained situations. 


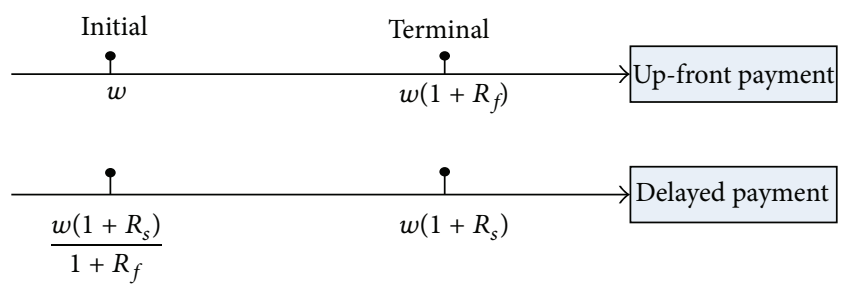

FIGURE 3: The retailer's price changes under both payments.

Lemma 1. The retailer's expected benefit $E \pi_{r}$ monotonously decreases as the supplier's discount price $w$ increases.

Proof. When $q \leq \widehat{q}_{2}, E \pi_{r}=p \int_{0}^{q} \bar{F}(x) d x+y\left(1+R_{f}\right)-$ $w q\left(1+R_{s}\right)$ under the delayed payment. Further, we get $d E \pi_{r} / d w=p \bar{F}(q)(d q / d w)-q\left(1+R_{s}\right)$. Utilizing the condition $d q / d w<0$ given in the literature [7] gains $d E \pi_{r} / d w<0$. When $q \geq \widehat{q}_{2}, E \pi_{r}=p \int_{\widehat{x}_{2}}^{q} \bar{F}(x) d x$. We get $d E \pi_{r} / d w=$ $p\left\{\left[\bar{F}(q)-V \bar{F}\left(\widehat{x}_{2}\right)\right](d q / d w)-\left(q\left(1+R_{s}\right) / p\right) \bar{F}\left(\widehat{x}_{2}\right)\right\}$, where $V=$ $w\left(1+R_{s}\right) / p$. Utilizing $\bar{F}(q)=V \bar{F}\left(\widehat{x}_{2}\right)$ and $d q / d w<0$ gets $d E \pi_{r} / d w<0$. Lemma 1 is proved. Similarly, Lemma 1 can be proved under the up-front payment.

\section{Supplier's Optimal Decision under the Delayed Payment}

4.1. Supplier's Delayed Optimal Compensation Interest Rate. The supplier's crucial decisions under the delayed payment involve its delayed compensation interest rate $R_{s}$ and its discount price $w$. The supplier's expected benefit under the delayed payment is as

$$
E \pi_{s}=E \min \left[w q\left(1+R_{s}\right), p \min (x, q)+y\right]-c q\left(1+R_{f}\right),
$$

where $w\left(1+R_{s}\right)$ is the retailer's delayed price, $w q\left(1+R_{s}\right)$ is the supplier's income when the retailer does not go bankrupt, and $c q\left(1+R_{f}\right)$ is the supplier's risk-free income.

Only when $w q\left(1+R_{s}\right) \leq p q$, the retailer under the delayed payment can obtain nonnegative expected benefits. The retailer needs to pay $w\left(1+R_{s}\right)$ per good at the end of the sale season. The order price at the beginning is equal to $w\left(1+R_{s}\right) /\left(1+R_{f}\right)$. Figure 3 shows the changes of price under both payments. According to the results of literature $[7,16]$, the order quantity shows a negative correlation with the price. Hence, the values of $R_{s}$ and $R_{f}$ determine the order quantity between both payments. When $R_{s}>R_{f}$, the retailer reduces its order quantity $q_{s}$ compared to the up-front payment.

Figure 4 illustrates the relationship among $R_{s}, q$, and $w$ under the delayed payment as a supplement of Figure 3 . The curves $a, b$, and $c$ correspond to the compensation the interest rate $R_{s a}>R_{s b}>R_{s c}$, respectively. When $R_{s}$ decreases, $q$ and $w$ first move from Curve $a$ to Curve $b$ and then move up to Curve $c$. This hints there is an increasing $E \pi_{s}$. Once $R_{s}<R_{f}$, the supplier's benefit will be less than the risk-free income. The supplier will choose to save its owned capital into the bank. The supplier never provides the delayed payment to its retailer. Hence, the supplier's optimal delayed compensation interest rate $R_{s}^{*}=R_{f}$.

When $q \leq \widehat{q}_{2}$, the curve is a down-convex shape. When $q>\widehat{q}_{2}$, the curve is an up-convex shape. The points of $\widehat{q}_{2, a}$, $\widehat{q}_{2, b}$, and $\widehat{q}_{2, c}$ in Figure 4 represent the inflection points on the curves $a, b$, and $c$, respectively. The theoretical proof and explanation refer to Appendix B.

4.2. Suppliers' Optimal Discount Price. The supplier's discount price $w$ falls into the interval $\left[c\left(1+R_{f}\right), p /\left(1+R_{s}\right)\right]$. If $w$ is less than $c\left(1+R_{f}\right)$, the supplier will not produce and turn to risk-free returns. Otherwise, if $w$ is greater than $p /\left(1+R_{s}\right)$, the retailer will have to pay $w\left(1+R_{s}\right)>p$ at the end of the sale season. The retailer has no profit and, hence, will not order goods. Similar to the analysis of literature [7] on the up-front payment, we derive the optimal discount price of the supplier under the delayed payment as follows.

Based on (3), the supplier's expected benefit $E \pi_{s}$ is rewritten:

$$
E \pi_{s}= \begin{cases}(w-c)\left(1+R_{f}\right) q, & q \leq \widehat{q}_{2}, \\ (w-c)\left(1+R_{f}\right) q+p \int_{0}^{\widehat{x}_{2}} \bar{F}(x) d x-p \widehat{x}_{2}, & q>\widehat{q}_{2} .\end{cases}
$$

By taking $d E \pi_{s} / d w=0$, we obtain the supplier's optimal discount price $w^{*}$ as follows:

$$
\begin{aligned}
& w^{*} \\
& =\left\{\begin{array}{cc}
c+\frac{p q f(q)}{1+R_{f}}, & q \leq \widehat{q}_{2}, \\
c+\frac{p V F\left(\widehat{x}_{2}\right)}{1+R_{f}} & \\
+\left(p q\left[f\left(\widehat{x}_{2}\right) V^{2}-f(q)\right]\right. & \\
\left.\times\left[\left(1+R_{s}\right) F\left(\widehat{x}_{2}\right)-\left(1+R_{f}\right)\right]\right) & \\
\times\left(\left(1+R_{f}\right)\left(1+R_{s}\right)\left[\bar{F}\left(\widehat{x}_{2}\right)-V q f\left(\widehat{x}_{2}\right)\right]\right)^{-1}, & q>\widehat{q}_{2},
\end{array}\right.
\end{aligned}
$$

where $V=w\left(1+R_{s}\right) / p$. And $w^{*}$ needs to satisfy the interval $\left[c\left(1+R_{f}\right), p /\left(1+R_{s}\right)\right]$.

Lemma 2. Given $R_{r}$ and $w$, the retailer's optimal order quantity $q_{s}^{*}$ under the delayed payment is greater than $q_{b}^{*}$ under the up-front payment.

Proof. Assume $R_{s}=R_{f}=R_{r}$. Under the Bertrand competition, this assumption is reasonable. We further obtain the critical condition $\widehat{q}_{1}=\widehat{q}_{2}=y / w=\hat{q}$ and $\widehat{x}_{1}=$ $\widehat{x}_{2}=(w q-y)\left(1+R_{f}\right) / p$. When $q \leq \hat{q}, \bar{F}\left(q_{1}\right)=\bar{F}\left(q_{2}\right)=$ $w\left(1+R_{f}\right) / p$. When $q>\hat{q}, \bar{F}\left(q_{1}\right)=\bar{F}\left(q_{2}\right)=(w(1+$ $\left.\left.R_{f}\right) / p\right) \bar{F}\left[(w q-y)\left(1+R_{f}\right) / p\right]$. This suggests that the retailer orders same quantity under two payments. And further the retailer and supplier earn the same expected benefit under both payments, respectively. 


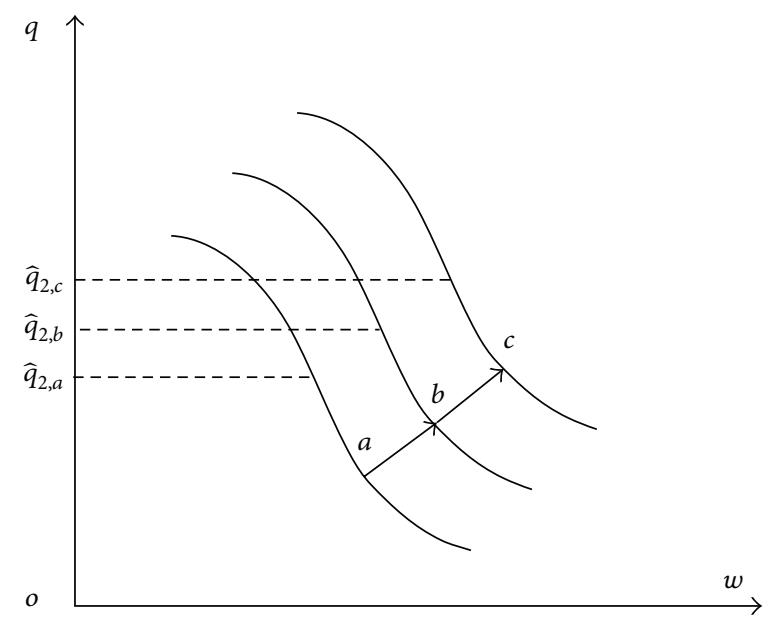

FIGURE 4: The illustration of relationship among $R_{s}, q$, and $w$.

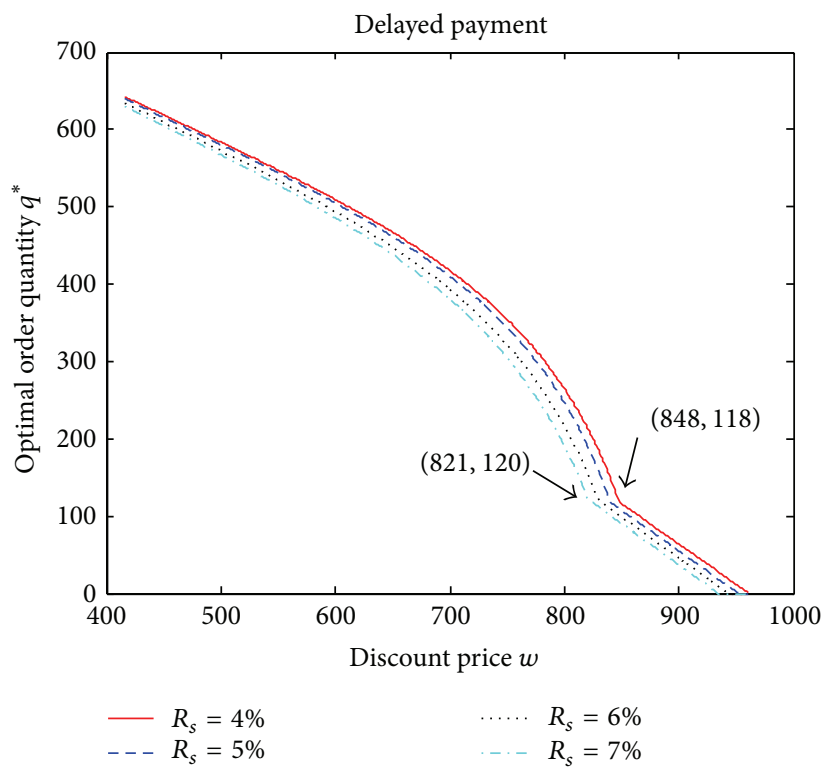

FIGURE 5: The changes of $q^{*}$ with $w$ at four different $R_{s}$.

Under the condition of $R_{s}=R_{f}=R_{r}$, the bank under the up-front payment suffers the loss despite the fact that it would not probably go bankrupt. In order to avoid the possible loss, the bank necessarily increases its lending interest rate, namely, $R_{r}>R_{f}[7,20]$. According to the literature [16], the higher interest rate reduces the retailer's optimal order quantity $q_{b}^{*}$, and further declines the expected benefits of the supplier and retailer. When $R_{s}=R_{f}<R_{r}$, the retailer under the delayed payment orders an optimal quantity $q_{s}^{*}>q_{b}^{*}$. Hence, the retailer and supplier under the delayed payment earn more expected benefits than earn under the up-front payment.

In order to compare the optimal decisions with the upfront payment, we list the results under both payments in Table 1.

\section{Numerical Simulation}

We design a simple supply chain to simulate financing order activities under the delayed and up-front payment. Here, the supplier is dominant participant and has enough credit to provide its capital-constrained retailer. The parameters of the numerical simulation are set as follows: $c=400 ; p=$ $1000 ; y=100000 ; R_{f}=4 \% ; R_{r}=8 \%$; and $\lambda=0.9$. The market demand $x$ is a random variable following the uniform distribution of the interval $[0,1000]$. Figure 5 shows the changes of $q^{*}$ at four different compensation interest rates. Points $(848,118)$ and $(821,120)$ are the inflection points on the curves of $R_{s}=4 \%$ and $R_{s}=7 \%$, respectively. When the retailer orders less quantity than a corresponding reflection point, the retailer does not go bankrupt. Figure 5 supports the theoretical results of Figure 4. 


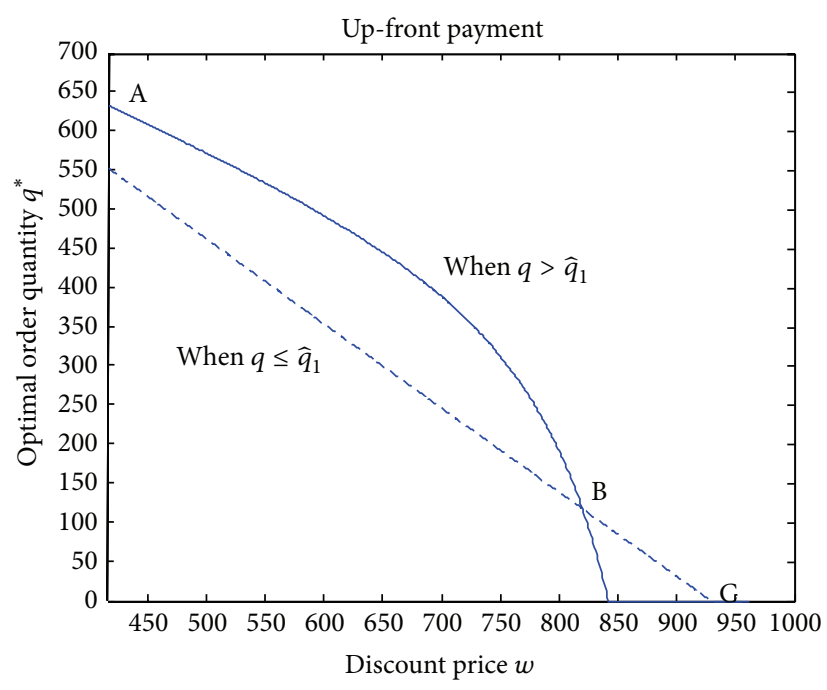

(a)

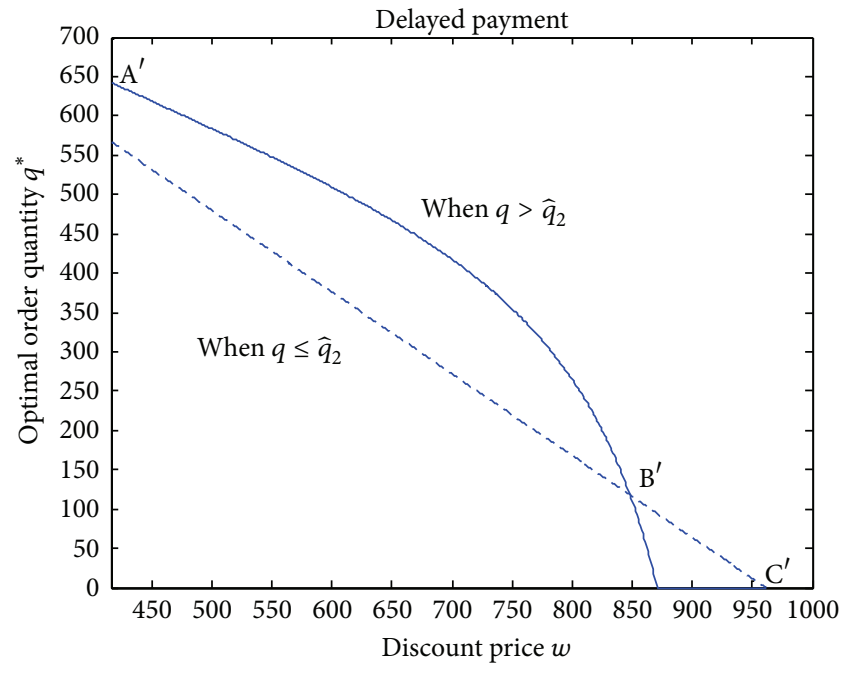

(b)

FIGURE 6: The changes of $q^{*}$ with $w$ for the retailer without bankruptcy.

TABLE 1: Comparison of the optimal decisions under the delayed and up-front payment.

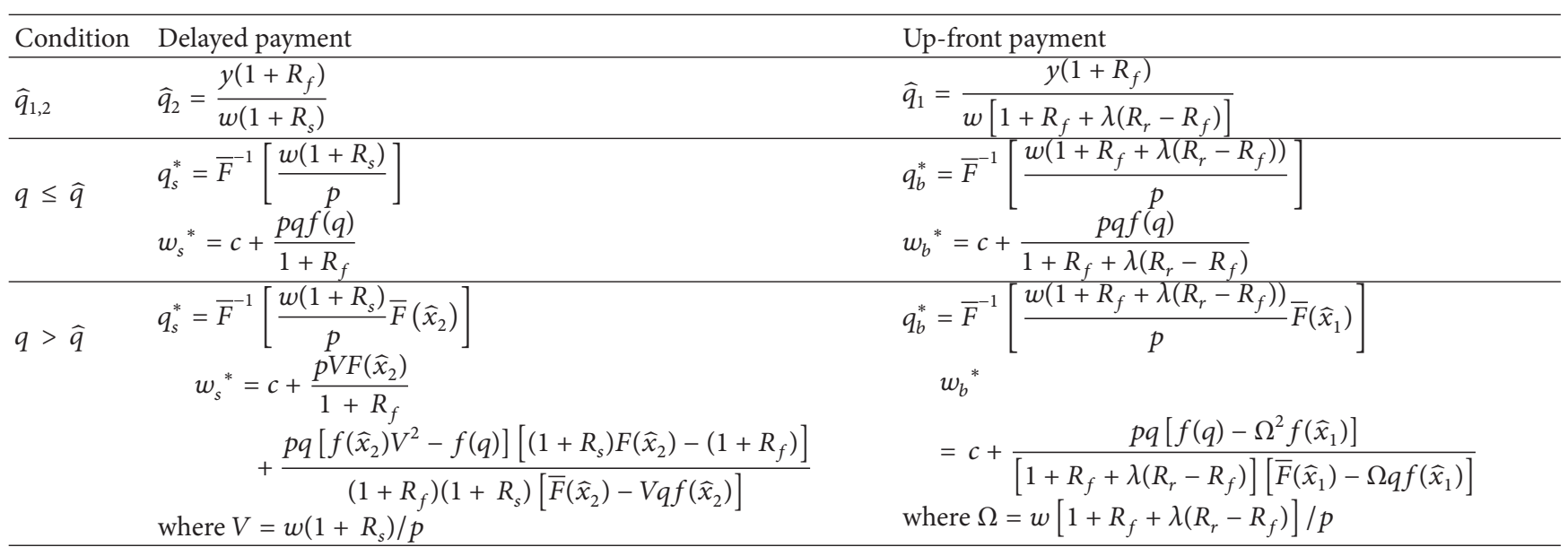

Note: The results of the up-front payment, listed on column 2, source from literature [7]. The unsold products have no salvage value.

When $R_{s}=4 \%$, the retailer orders a maximum $q^{*}$ and, hence, earns greatest expected $\pi_{r}$ at given $p$. The results indicated by Figure 5 are consistent with our previous theoretical analysis, namely, $R_{s}^{*}=R_{f}$, which is shown in Section 4 . Hereafter, we use $R_{s}=4 \%$ to analyze the changes among $q^{*}, w, \pi_{r}$, and $\pi_{s}$.

We further investigate how $q^{*}$ changes as $w$. Figure 6(a) illustrates the change of $q_{b}^{*}$ with $w$ under the up-front payment. The solid line represents the response curve of $q_{b}^{*}$ to $w$ when $q \geq \widehat{q}_{1}$. The dashed line represents the response curve of $q_{b}^{*}$ to $w$ when $q \leq \hat{q}_{1}$. The retailer will order quantity on the curve $\mathrm{ABC}$ as its optimal order decision. Figure 6(b) shows the response curve of $q_{b}^{*}$ to $w$ under the delayed payment. Similarly, the order quantity on the curve $\mathrm{A}^{\prime} \mathrm{B}^{\prime} \mathrm{C}^{\prime}$ is the retailer's optimal order decision. Figure 6 shows that $q^{*}$ decreases as $w$ increases. This result indicates that there exists an inverse correlation between $q^{*}$ and $w$ under the delayed payment. Points $(820,117)$ and $(848,118)$ are the reflection points on the curves of the up-front and delayed payment, respectively.

Figure 7 compares the changes of $q^{*}$ as $w$ under two payments. The curve $\mathrm{A}^{\prime} \mathrm{B}^{\prime} \mathrm{C}^{\prime}$, which represents the retailer's optimal order decision, always is above the curve $\mathrm{ABC}$ being the retailer's optimal order decision. This means that the retailer will order more under the delayed payment. The retailer, therefore, will have a higher expected benefit at a certain price $p$. Figure 7 supports Lemma 2.

Table 2 shows that the retailer's expected revenue $E \pi_{r}$ declines as $w$ increases, while the supplier's expected revenue $E \pi_{s}$ first increases and then decreases. This indicates that $w$ as a crucial factor obviously influences the expected benefit $E \pi$. When facing an uncertain market demand $x$, a lower $w$ will bring the retailer a higher $E \pi_{r}$. This evidence supports Lemma 1 . However, since a lower $w$ reduces the supplier's 
TABLE 2: The expected benefits under the delayed and up-front payment.

\begin{tabular}{lcccccccc}
\hline Payment & $w$ & 620 & 660 & 700 & 740 & 780 & 820 & 860 \\
\hline \multirow{4}{*}{ Delayed } & $q_{s}$ & 493 & 458 & 418 & 369 & 305 & 215 & 106 \\
& $E \pi_{r}$ & 15.76 & 14.27 & 13.04 & 12.10 & 11.50 & 11.26 & 11.00 \\
& $E \pi_{s}$ & 9.00 & 10.17 & 11.03 & 11.40 & 11.00 & 9.06 \\
\hline \multirow{2}{*}{ Up-front } & Total benefit & 24.76 & 24.44 & 24.07 & 23.50 & 22.50 & 20.32 & 16.05 \\
& $q_{b}$ & 474 & 435 & 389 & 330 & 248 & 117 & 74 \\
& Total benefit & 24.17 & 23.79 & 23.3 & 22.52 & 20.90 & 16.38 & 14.11 \\
\hline
\end{tabular}

Note: The total benefit under the up-front payment involves a supplier, a retailer, and a bank. The benefit listed on Table 2 times 104 .

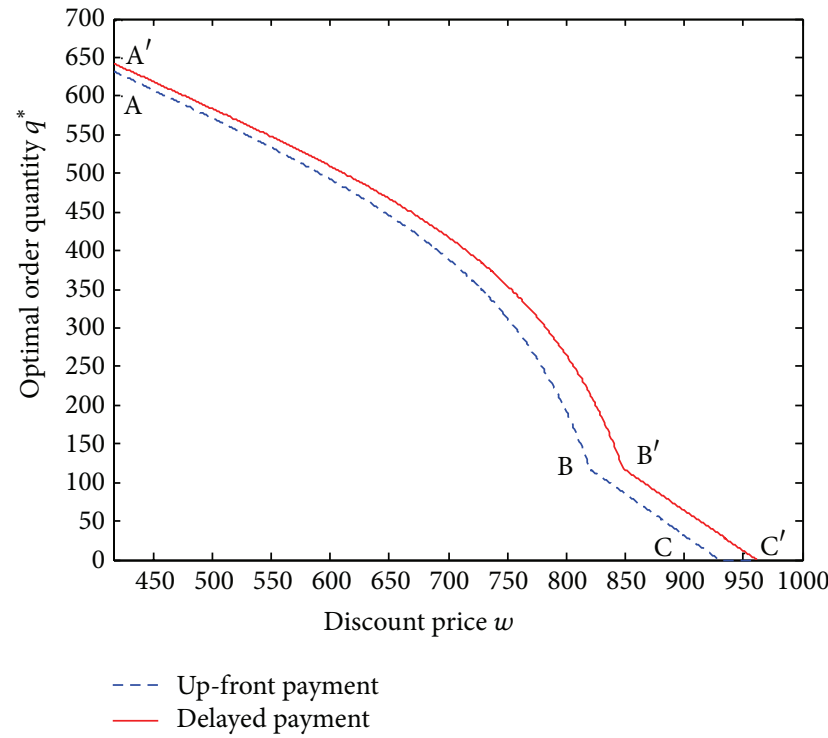

Figure 7: The changes of $q^{*}$ with $w$ under both payments.

expected benefit $E \pi_{s}$ although it probably receives a higher $q_{s}^{*}$. When $q_{s}^{*}=363, w^{*}=744$, and $R_{s}^{*}=4 \%$, this supply chain under the delayed payment reaches its equilibrium. The total benefit, involving a supplier and a retailer, is equals 23.45 $\times 10^{4}$. When $q_{b}^{*}=362$ and $w^{*}=720$, the supply chain under the up-front payment reaches its equilibrium. The total benefit, involving a supplier, a retailer and a bank, is $22.97 \times$ $10^{4}$. The result suggests that the delayed payment improves the whole efficiency of the supply chain compared with the up-front payment. Table 2 directly supports Lemma 2.

\section{Conclusion}

We analyze the optimal financing order decisions of a simple supply chain consisting of a supplier, a capital-constrained retailer, and a commercial bank. Specifically, we compare the optimal decisions under the up-front payment with under the delayed payments. Our finding are four folded: (1) the retailer's optimal order quantity under two types of payments declines as the supplier's quoted price increases when the retailer is in healthy financial status; (2) under the delayed payment, the retailer earns maximum expected benefit when the supplier's compensation interest rate is equal to the risk-free interest rate; (3) the price quoted by the supplier plays a crucial factor that significantly impacts the expected benefits of all participants, the supplier, the retailer, and the bank; and (4) when quoted prices are identical, the delayed payment enables the retailer to order more quantity than the up-front payment. This suggests that internal trade credit efficiently enhances the whole efficiency of the supply chain than external financing. The numerical simulation confirms our theoretical results. Hence, when encountering capital constrain, the retailer can use internal financing to achieve a higher whole efficiency.

\section{Appendices}

\section{A. Proof of $E[\min (x, q)]=\int_{0}^{q} \bar{F}(x) d x$}

Let

$$
I A(z)= \begin{cases}I A(z)=1, & z \in A \\ I A(z)=1, & z \notin A,\end{cases}
$$

where $I A(\cdots)$ denotes an indicative function.

$E[\min (x, q)]$ can be written $E[\min (x, q)]=E[x I A(x<$ $q)+q \operatorname{IA}(x>q)]$

$$
\begin{aligned}
E[\min (x, q)]= & \int_{0}^{+\infty} x I A(x<q) f(x) d x \\
& +\int_{0}^{+\infty} q I A(x>q) f(x) d x \\
= & \int_{0}^{q} x f(x) d x+\int_{q}^{+\infty} q f(x) d x \\
= & \int_{0}^{q} x f(x) d x, \\
\int_{0}^{q} \bar{F}(x) d x= & \int_{0}^{q}(1-F(x)) d x \\
= & {\left.[1-F(x)] x\right|_{0} ^{q}+\int_{0}^{q} x f(x) d x } \\
= & \int_{0}^{q} x f(x) d x, \\
E[\min (x, q)]= & \int_{0}^{q} \bar{F}(x) d x .
\end{aligned}
$$




\section{B. Proof of Figure 4}

Give

$$
F(x)=\left\{\begin{array}{ll}
1-e^{-t x}, & x>0, \\
0, & x \leq 0,
\end{array} \quad f(x)= \begin{cases}t e^{-t x}, & x>0 \\
0, & x \leq 0,\end{cases}\right.
$$

where $t>0$.

(1) When $q \leq \widehat{q}_{2}$, let $a=\left(1+R_{s}\right) / p$. One gets $0<a w=$ $w\left(1+R_{s}\right) / p<1$.

$q=-\frac{1}{t} \ln (a w) ; \quad q_{w}^{\prime}=-\frac{1}{t w}<0 ; \quad q_{w}^{\prime \prime}=\frac{1}{t w^{2}}>0$.

The curve is a down-convex shape.

(2) When $q>\widehat{q}_{2}$,

$$
\begin{aligned}
q & =\frac{1}{a w-1}\left[\frac{\ln (a w)}{t}+a y\right] ; \\
q_{w}^{\prime} & =\frac{(1 / w)(a w-1)-a[\ln (a w)+t a y]}{t(a w-1)^{2}}<0 ; \\
q_{w}^{\prime \prime} & =\frac{1}{t(a w-1)^{3}}\left[\frac{1}{w^{2}}(a w-1)-\frac{3 a}{w}(a w-1)\right. \\
& \left.+2 a^{2}(\ln (a w)+\text { tay })\right]<0 .
\end{aligned}
$$

when $y \gg p>w \gg a, q_{w}^{\prime}<0$ and $q_{w}^{\prime \prime}<0$.

The curve is an up-convex shape.

\section{Conflict of Interests}

The authors declare that there is no conflict of interests regarding the publication of this paper.

\section{Acknowledgments}

Aids from the National Natural Science Foundation of China under Grant nos. 71073049, 71210107022, 71371008, 71001093, and 71272084 and the Program for New Century Excellent Talents in University under Grant no. NCET-13-0193, and the Ministry of Education in China of Humanities and Social Science Project under Grant no. 14YJA630077 are gratefully acknowledged. The authors also thank the valuable advices from Dr. Feng Wang and Ph.D. candidate Wenyan Zhuo.

\section{References}

[1] P. Vandenberg, "Adapting to the financial landscape: evidence from small firms in Nairobi," World Development, vol. 31, no. 11, pp. 1829-1843, 2003.

[2] T. R. Poe, "Subjective judgments and the asset-based lender," Commercial Lending Review, vol. 13, no. 2, pp. 67-70, 1998.
[3] M. A. Petersen and R. G. Rajan, "Trade credit: theories and evidence," Review of Financial Studies, vol. 10, no. 3, pp. 661-691, 1997.

[4] J. A. Buzacott and R. Q. Zhang, "Inventory management with asset-based financing," Management Science, vol. 50, no. 9, pp. 1274-1292, 2004.

[5] X. Xu and J. R. Birge, "Joint production and financing decisions: modeling and analysis," Working Paper, 2004.

[6] M. Dada and Q. Hu, "Financing newsvendor inventory," Operations Research Letters, vol. 36, no. 5, pp. 569-573, 2008.

[7] N. Yan and B. Sun, "Optimal strategies for supply chain financing system based on warehouse receipts financing with credit line," System Engineering Theory and Practice, vol. 11, no. 9, pp. 1674-1679, 2011.

[8] X. Chen, M. Sim, D. Simchi-Levi, and P. Sun, "Risk aversion in inventory management," Operations Research, vol. 55, no. 5, pp. 828-842, 2007.

[9] R. Fisman and I. Love, "Trade credit, financial intermediary development and industry growth," Journal of Finance, vol. 58, no. 1, pp. 353-374, 2003.

[10] S. K. Goyal, "Economic order quantity under conditions of permissible delay in payments," Journal of the Operational Research Society, vol. 36, no. 4, pp. 335-338, 1985.

[11] S. P. Aggarwal and C. K. Jaggi, "Ordering policies of deteriorating items under permissible delay in payments," The Journal of the Operational Research Society, vol. 46, no. 5, pp. 658-662, 1995.

[12] M. K. Salameh, N. E. Abboud, A. N. El-Kassar, and R. E. Ghattas, "Continuous review inventory model with delay in payments," International Journal of Production Economics, vol. 85, no. 1, pp. 91-95, 2003.

[13] F. J. Arcelus and G. Srinivasan, "Delay of payments for extraordinary purchases," The Journal of the Operational Research Society, vol. 44, no. 8, pp. 785-795, 1993.

[14] J. Zhou and H. Groenevelt, "Impacts of financial collaboration in a three-party supply chain," Working Paper, 2008.

[15] D. Gupta, "Technical note: financing the newsvendor," Working Paper, 2008.

[16] P. Kouvelis and W. Zhao, "Financing the newsvendor: supplier vs. bank, and the structure of optimal trade credit contracts," Operations Research, vol. 60, no. 3, pp. 566-580, 2012.

[17] L. Wang and J. Luo, "Strategies for financing suppliers based on retailers' prepayment and loan guarantee," Journal of Industrial Engineering and Engineering Management, vol. 27, no. 1, pp. 178184, 2013.

[18] Y. W. Zhou, Y. G. Zhong, and M. I. M. Wahab, "How to make the replenishment and payment strategy under flexible two-part trade credit," Computers \& Operations Research, vol. 40, no. 5, pp. 1328-1338, 2013.

[19] M. Y. Jaber and I. H. Osman, "Coordinating a two-level supply chain with delay in payments and profit sharing," Computers and Industrial Engineering, vol. 50, no. 4, pp. 385-400, 2006.

[20] H. C. Pfohl and M. Gomm, "Supply chain finance: optimizing financial flows in supply chains," Logistics Research, vol. 1, no. 3-4, pp. 149-161, 2009. 


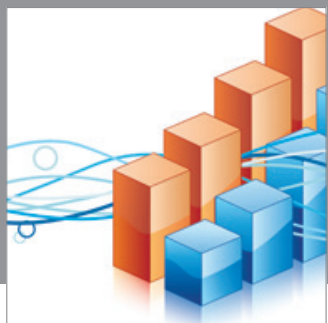

Advances in

Operations Research

mansans

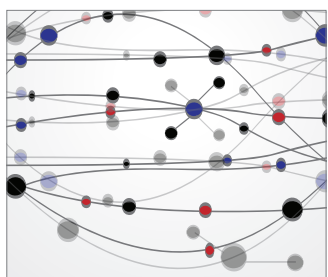

The Scientific World Journal
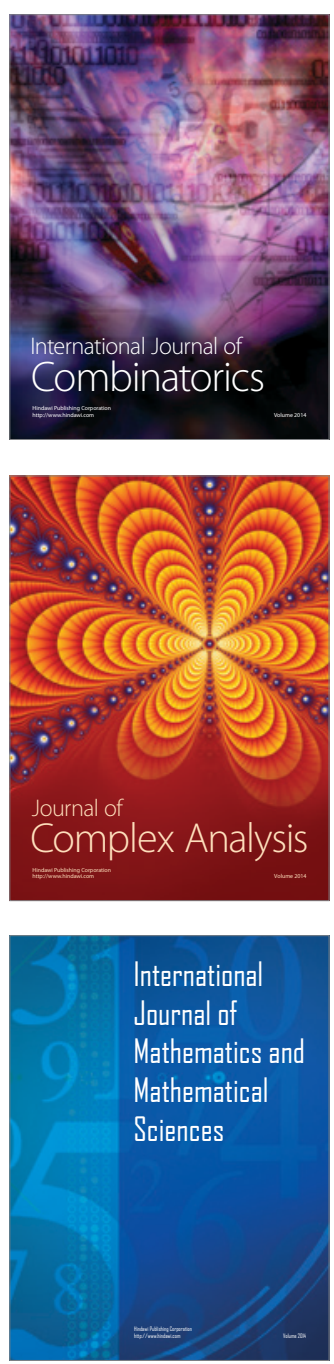
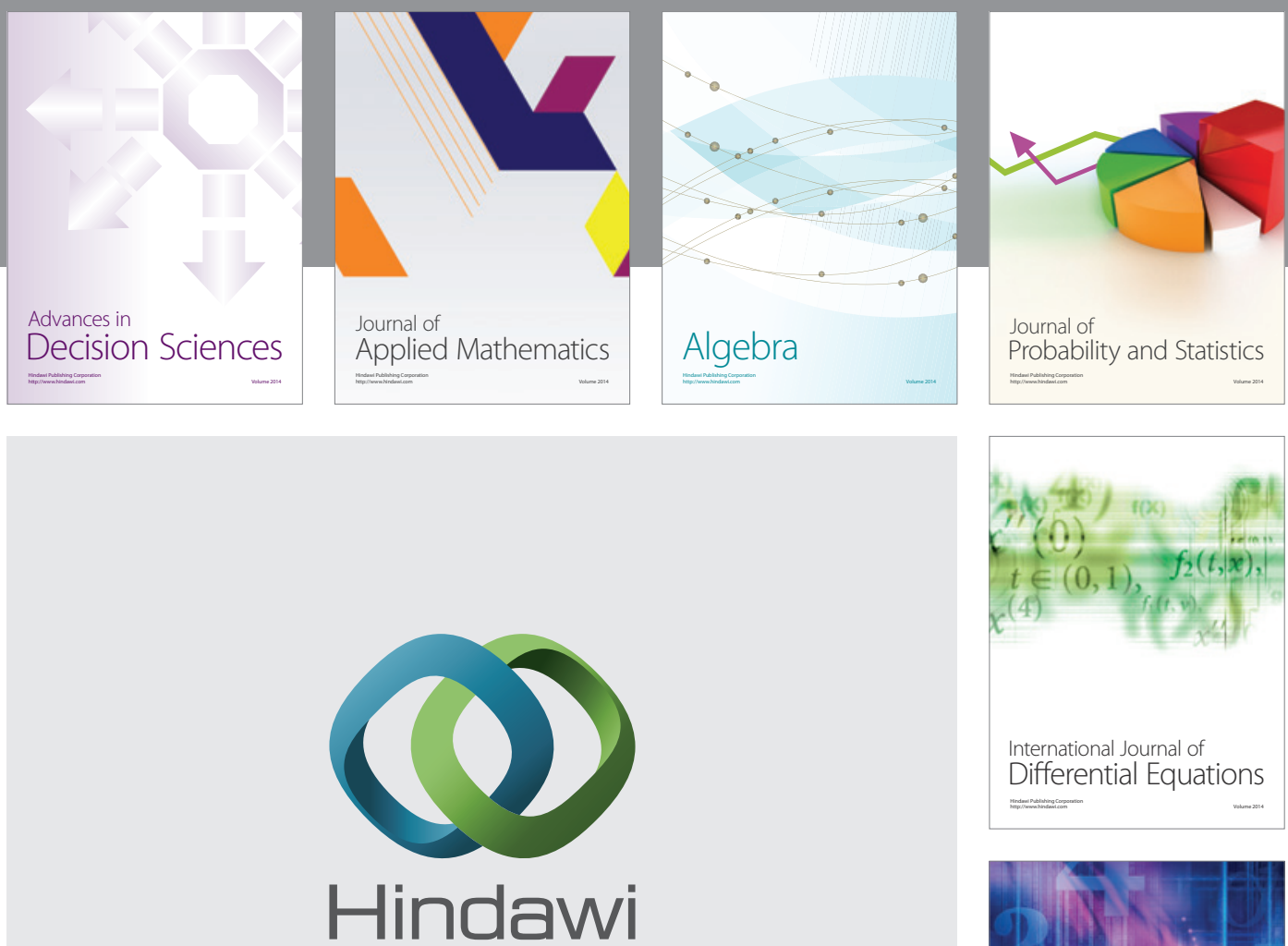

Submit your manuscripts at http://www.hindawi.com
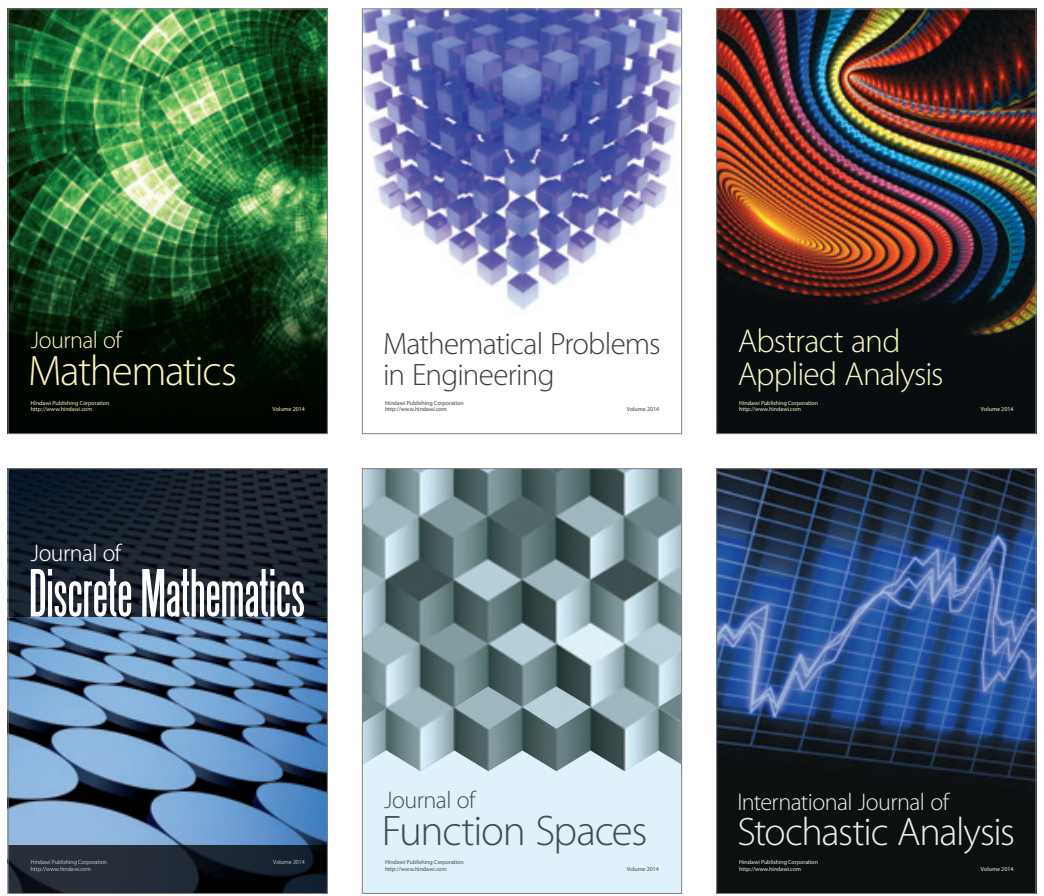

Journal of

Function Spaces

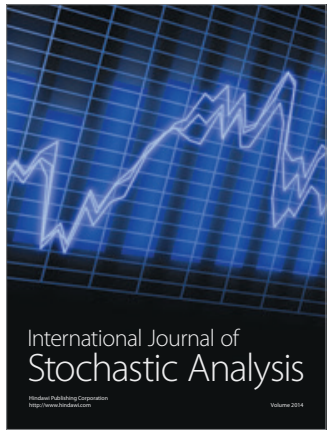

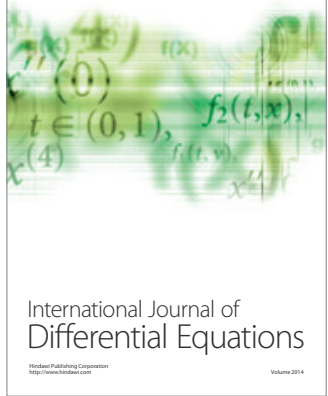
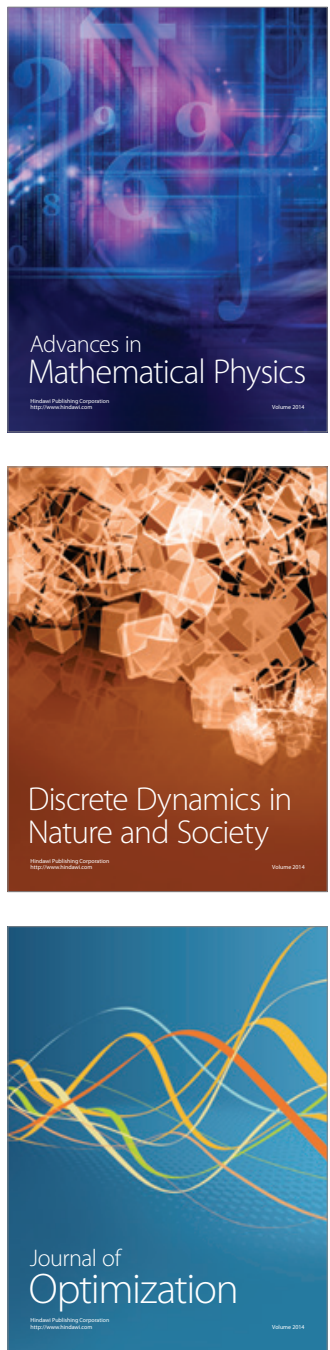